\title{
A!
}

This is an electronic reprint of the original article.

This reprint may differ from the original in pagination and typographic detail.

Thomas, Chris I.; Karppinen, Maarit

\section{Intercalation of Primary Alcohols into Layered Titanoniobates}

Published in:

Inorganic Chemistry

DOI:

10.1021/acs.inorgchem.7b01135

Published: 07/08/2017

Document Version

Peer reviewed version

Published under the following license:

Unspecified

Please cite the original version:

Thomas, C. I., \& Karppinen, M. (2017). Intercalation of Primary Alcohols into Layered Titanoniobates. Inorganic Chemistry, 56(15), 9132-9138. https://doi.org/10.1021/acs.inorgchem.7b01135

This material is protected by copyright and other intellectual property rights, and duplication or sale of all or part of any of the repository collections is not permitted, except that material may be duplicated by you for your research use or educational purposes in electronic or print form. You must obtain permission for any other use. Electronic or print copies may not be offered, whether for sale or otherwise to anyone who is not an authorised user. 


\title{
Intercalation of primary alcohols into layered titanoniobates
}

\author{
Chris I. Thomas* and Maarit Karppinen \\ Department of Chemistry and Materials Science, Aalto University, FI-ooo76, Espoo, Finland. \\ Received Date
}

\begin{abstract}
Lamellar oxides form an important class of functional materials and are often susceptible to topotactic substitution of the ions between the layers. This opens up the structure to direct reactions with alkylammonium ions often substituting for group one ions forcing an increase in layer separation. Proton exchange with group one ions is also possible in mineral acids with the resulting protonated materials typically being acidic. These solid acids can further react with bases such as alkyl amines again causing an increase in interlayer separation. Alcohols do not readily form stable $\mathrm{ROH}_{2}{ }^{+} \mathrm{X}^{-}(\mathrm{R}$ alkyl chain, $\mathrm{X}$ halide) species and being less basic than $\mathrm{RNH}_{2}$ are less commonly investigated for intercalation into layered oxides. Here the intercalation of simple primary alcohols of the form $\mathrm{ROH}\left(\mathrm{R}=\mathrm{C}_{\mathrm{x}} \mathrm{H}_{2 \mathrm{x}+1} ; \mathrm{x}=1-10\right)$ is investigated using the layered titanoniobate $\mathrm{HTiNbO}_{5}$ as the ceramic host. Direct reaction is found to be ineffective so instead butylamine is first intercalated followed by reaction with the primary alcohols. The butylamine remains in the final product but intercalation of the alcohols causes a significant modification of the interlayer space of the ceramic. This shows how alcohols can be used to influence the interlayer space of oxide sheets in functional layered oxide ceramics.
\end{abstract}

\section{Introduction}

Layered compounds are investigated extensively worldwide with a view to producing new advanced materials through the intercalation of guest species into a two-dimensional host. ${ }^{1,2,3,4} \mathrm{~A}$ wide variety of properties can be affected by the interaction of the ceramic and intercalant. For example the loading capacity of carbon capture and storage materials ${ }^{5}$ and the properties of high temperature solid lubricants. ${ }^{6}$ Sometimes the release of the intercalant

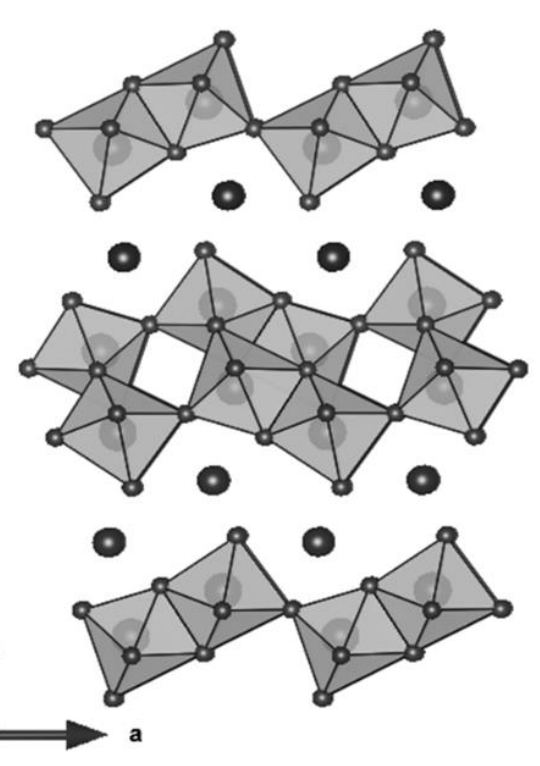

Figure $1 \mathrm{KTiNbO}_{5}$ viewed down the $\mathrm{b}$ axis with $\mathrm{Ti} / \mathrm{Nb}$ Octahedra and $\mathrm{K}$ circles. The octahedra form edge shared pairs linked by corner sharing forming sheets. under controlled conditions is important such as the gradual release of intercalated medicines ${ }^{7}$ or fertilizers. ${ }^{8}$ Due to interfaces scattering phonons, hybrid multilayer superlattices are of great interest for thermoelectric materials. For example thin films with $\mathrm{ZnO} /$ hydroquinone superlattices show a significant decrease in the thermal conductivity compared to pure $\mathrm{ZnO}$ films. ${ }^{9} \mathrm{TiS}_{2}$ is a layered compound that when hexylammonium is intercalated shows a thermal conductivity reduction of two orders of magnitude compared to pure $\mathrm{TiS}_{2}{ }^{10}$

In addition to affecting physical properties intercalation can also influence the electronic properties. When diamines are intercalated in the semiconducting $\mathrm{TiNCl}$ the material becomes superconducting with transition temperatures ranging from 6.8 to $17.1 \mathrm{~K} .{ }^{11} \mathrm{By}$ intercalating molecular spacers in FeSe the superconducting transition temperature can be enhanced. ${ }^{12}$ A review of intercalation in iron chalcogenide superconductors by Vivanco and Rodriguez ${ }^{13}$ suggests that tuning the transition temperature up to $45 \mathrm{~K}$ via intercalation is possible. Intercalation can affect superconductivity in other systems such as the superconducting cuprates. The high pressure synthesized $\mathrm{Ba}_{2} \mathrm{Ca}_{2} \mathrm{Cu}_{3} \mathrm{O}_{8+\delta}$ for example has a $\mathrm{T}_{\mathrm{c}}$ of $126 \mathrm{~K}$ when dry but another superconducting phase with $\mathrm{T}_{\mathrm{c}} \approx 90 \mathrm{~K}$ forms on intercalation of water. ${ }^{14}$ Water intercalates into many other materials with rock salt blocks. $\mathrm{Sr}_{3} \mathrm{Fe}_{2} \mathrm{O}_{7}$ has two water derivatives as well as a dry form, all three exhibit different magnetic behavior. ${ }^{15}$

A further example of the versatility of layered intercalation compounds is in the field of heterogeneous photocatalysts. ${ }^{16,17}$ Here often the inorganic material provides the catalytic centers and the organic component is used to either as a photon collector ${ }^{18}$ or to increase the active surface area. ${ }^{19}$ Compounds of titanium oxide and niobium oxide 
are attracting significant interest due to their semiconducting nature and ability as UV catalysts. ${ }^{20}$

There are many possible layered inorganic host materials such as layered double hydroxides (LDHs), ${ }^{21}$ RuddlesdenPopper ${ }^{22}$ and Dion-Jacobson phases. ${ }^{23}$ In the present work, $\mathrm{KTiNbO}_{5}$, described as having a lepidocrocite ( $\left.\mathrm{\gamma}-\mathrm{FeOOH}\right)$ related structure, ${ }^{24}$ is investigated. The structure of the $\mathrm{KTiNbO}_{5}$ parent structure is shown in Figure 1 where sheets of $\mathrm{TiNbO}_{5}{ }^{-}$are separated by $\mathrm{K}^{+}$. The sheets consist of pairs of edge shared octahedra linked via corner sharing forming zigzag strings. Each layer can be considered 'antiparallel with the layers above and below. The potassium ions reside in a distorted pseudo cubic environment between sheets. Similar compounds can be made with $\mathrm{Rb}^{+}$, $\mathrm{Tl}^{+}$or $\mathrm{Cs}^{+}$but $\mathrm{Na}^{+}$and $\mathrm{Li}^{+}$cause the $\mathrm{TiNbO}_{5}{ }^{-}$layers to adopt a 'parallel' configuration. ${ }^{25,26}$ These monovalent ions can be exchanged out for protons ${ }^{27}$ before further reaction with n-alkyl amines. Further reaction allows large molecules such as methylene blue, ${ }^{28}$ Rhodamine $6 \mathrm{G},{ }^{29}$ porphy$\operatorname{rin}^{30,31}$ and polymers such as polyaniline ${ }^{32}$ to then be incorporated.

Intercalation of n-alkyl alcohols has so far been overlooked as direct reaction appears unsuccessful. In addition $\mathrm{HTiNbO}_{5}$ is a solid acid catalyst that has been shown to dehydrate secondary alcohols.33,34 It is this acidity that allows intercalation of the basic amines (amines with pKa > 6) 35 using a proton donation mechanism. Primary alcohols are less basic than primary amines explaining the lack of reaction of $n$-alkyl alcohols. Competition reactions using lower alcohols, amines and $\mathrm{HTiNbO}_{5}$ also appear to be unsuccessful. Previous work by Rebbah et $\mathrm{al}^{27}$ found using a $50 \%$ alcohol to amine solution could be used instead of neat amine 'without changing the results'.

Alcohols, however, have been grafted into the interlayer space of the $n=3$ Ruddlesden-Popper phase $\mathrm{H}_{2} \mathrm{La}_{2} \mathrm{Ti}_{3} \mathrm{O}_{10}$ with Ti-O-C bonds being formed.22 The process goes through an amine intercalate intermediate, again formed via acid base reaction giving $\mathrm{RNH}_{3}{ }^{+}$ions at the proton sites. The reaction with alcohols appears to graft the alkyl part of the alcohol to the metal oxygen octahedra, the hydroxide and proton form water freeing the amine.

In this paper we show the intercalation of primary alcohols of carbon chain length 1 -10 between the $\left(\mathrm{TiNbO}_{5}\right)^{-}$ layers of $\left(\mathrm{RNH}_{3}\right)+\left(\mathrm{TiNbO}_{5}\right)$ - intermediates.

\section{Experimental}

\section{Synthesis}

$\mathrm{KTiNbO}_{5}$ was first synthesized by grinding stoichiometric amounts of $\mathrm{K}_{2} \mathrm{CO}_{3}$ (Alfa Aesar, 99.0\%), $\mathrm{TiO}_{2}$ (Alfa Aesar, 99.5 \%) and $\mathrm{Nb}_{2} \mathrm{O}_{5}$ (Alfa Aesar, 99.95\%) together, pressing into $13 \mathrm{~mm}$ pellets and firing in air at $1100{ }^{\circ} \mathrm{C}$ for 12 hours. Then the material was ground and soaked in $2 \mathrm{M}$ $\mathrm{HCl}$ (Alfa Aesar 32\% diluted with distilled water) for 12 hours, before being filtered and washed with distilled water to remove excess acid and $\mathrm{KCl}$. The powder was then dried in a fumehood giving $\mathrm{HTiNbO}_{5}$. The resulting white powder was then heated to $70{ }^{0} \mathrm{C}$ in a sealed vessel (Teflon lined Parr autoclave) with excess butylamine (Sigma-Aldrich > 99\%). The conditions used were not solvothermal rather used as a convenient way to contain fumes.

After filtering and drying in a fumehood the (ButylNH$\left.)_{2}\right)_{x} \mathrm{HiNbO}_{5}$ was then heated to $70{ }^{\circ} \mathrm{C}$ in a sealed vessel ( Teflon lined Parr autoclave) with excess neat primary alcohols methanol $\left(\mathrm{CH}_{3} \mathrm{OH}\right)$ to decanol $\left(\mathrm{C}_{10} \mathrm{H}_{21} \mathrm{OH}\right)$ (all > $98 \%)$. Resulting white powders were filtered and again dried in a fumehood.

\section{Characterization}

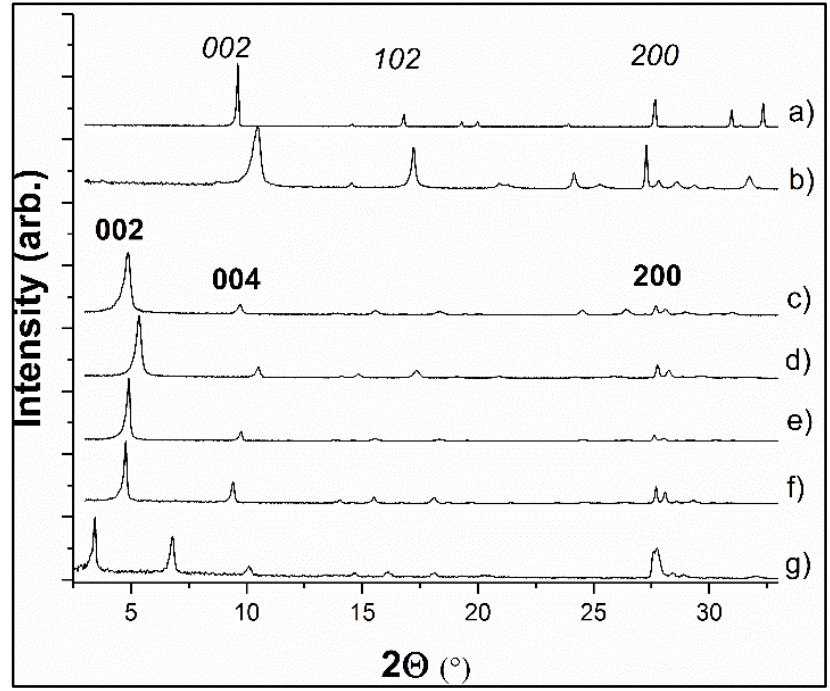

Figure 2 XRD patterns for a) original ceramic $\left(\mathrm{KTiNbO}_{5}\right)$, b) Proton exchanged ceramic $\left.\left(\mathrm{HTiNbO}_{5}\right), \mathrm{c}\right)$ amine intercalated ((butylNH$\left.)_{2}\right)_{\mathrm{XTiNbO}}$ ) and d) -g) alcohol intercalated (butylNH$)_{2}(\mathrm{ROH})_{\mathrm{y}} \mathrm{HTiNbO}_{5}$ where d) methanol e)butanol f)hexanol and g)decanol. Significant Miller indices in italics for a) and b) and bold for c)-g)

Powder X-ray diffraction (XRD) was carried out on a monochromated $\mathrm{Cu}$ source $(\mathrm{K} \alpha 1, \lambda=1.54056 \AA)$ PANalytical X'Pert Pro diffractometer operated at $45 \mathrm{kV} 40 \mathrm{~mA}$. Le Bail $^{36}$ and Rietveld 37 analysis was carried out using the General Structure Analysis System (GSAS) suite of programs $^{38}$ with the EXPGUI 39 user interface.

Thermogravimetric analysis (TGA) data were recorded on a Perkin Elmer Pyris thermal balance with a high temperature furnace using a $40 \mathrm{ml} \mathrm{m^{-1 }}$ nitrogen gas stream. During the heating cycle the temperature was increased at a rate of $1{ }^{\circ} \mathrm{C}$ per minute to $1000{ }^{\circ} \mathrm{C}$. The cooling was either carried out radiatively to $300{ }^{\circ} \mathrm{C}$ upon which the furnace detached exposing samples to air (denoted radiatively cooled) or at $1^{0} \mathrm{C}$ per minute to $30{ }^{\circ} \mathrm{C}$ (denoted slow cool).

Fourier transform infrared spectroscopy (FTIR) was carried using a Nicolet PROTÉGÉ 46o spectrometer measurement range $500 \mathrm{~cm}^{-1}$ to $4000 \mathrm{~cm}^{-1}$ with a resolution of $4 \mathrm{~cm}^{-}$ ${ }^{1}$. The measurement was carried out in transmission mode using $13 \mathrm{~mm}$ diameter $\mathrm{KBr}$ disks containing $200 \mathrm{mg}$ of dried $\mathrm{KBr}$ and $1 \mathrm{mg}$ of sample.

Carbon hydrogen and nitrogen $(\mathrm{CHN})$ analysis was carried out using a Perkin Elmer CHNS/O 2400 series II. 


\section{Results}

Primary alkyl alcohols with chain lengths of between 1 and 10 have successfully been intercalated between titanoniobate sheets. All samples are white crystalline powders making X-ray diffraction the primary method of analysis.

\section{Powder X-ray diffraction results}

The crystal structure of the parent $\mathrm{KTiNbO}_{5}$ was described by Wadsley in $1964 .^{\circ}$ Wadsley reported the Ti and $\mathrm{Nb}$ being present at random in two positions. However diffuse streaks were ascribed to 'short range order accompanying the random distribution'. Latter x-ray diffraction and neutron diffraction work by Rebbah et al. ${ }^{25,41}$ on both $\mathrm{KTiNbO}_{5}$ and $\mathrm{DTiNbO}_{5}$ reports $0.77: 0.23$ site selectivity. Sugimoto et al.42 also report site selectivity of $0.80(1): 0.20(1)$.

Rietveld refinement of the original $\mathrm{KTiNbO}_{5}$ gives lattice parameters (Pnma, $\mathrm{a}=6.44288(3) \AA, \mathrm{b}=3.79635(2) \AA \mathrm{A}, \mathrm{c}=$ 18.3851(1) $\AA$ in agreement with Wadsley ${ }^{40}($ Pnma a $=6.46 \AA$ $\mathrm{b}=3.79 \AA, \mathrm{c}=18.47 \AA$ ). The Rebbah ${ }^{4,43}$ model of preferential order of $\mathrm{Ti}$ and $\mathrm{Nb}$ in $\mathrm{DTiNbO}_{5}$ was used as starting point giving values of $0.781(3): 0.220(3)$ (supplementary data $\mathrm{S} 1-3)$.

All PXRD patterns can be indexed to orthorhombic cells consistent with space group Pnma $\left(\mathrm{KTiNbO}_{5}, \mathrm{HTiNbO}_{5}\right.$ $\left(\text { ButylNH }{ }_{2}\right)_{\mathrm{x}} \mathrm{HTiNbO}_{5}, \quad\left(\text { ButylNH }{ }_{2}\right)_{\mathrm{x}}\left(\mathrm{C}_{2} \mathrm{H}_{5} \mathrm{OH}\right)_{\mathrm{y}} \mathrm{HTiNbO}_{5}$ (ButylNH $\left.{ }_{2}\right)_{x}\left(\mathrm{C}_{10} \mathrm{H}_{21} \mathrm{OH}\right)_{y} \mathrm{HTiNbO}_{5}$ shown in figure 2 all other samples supplementary figure $\mathrm{S}_{5}$. As proton positions cannot be refined using X-ray radiation, Le Bail refinement was carried out to determine the lattice parameters for the $\mathrm{HTiNbO}_{5}$ unit cell $(\mathrm{a}=6.5279(5) \AA, \mathrm{b}=$ 3.7740 (2) $\AA, \mathrm{c}=16.704(3) \AA$ ). Le Bail refinements were also performed for all of the intercalated samples with the lattice parameters given in the supplementary table $\mathrm{S}_{4}$. As expected as the size of the intercalated molecule gets larger the c parameter increases but $\mathrm{a}$ and $\mathrm{b}$ parameters remain constant $(\mathrm{a} \approx 6.47(2) \AA \AA \mathrm{b} \approx 3.795(10) \AA)$.

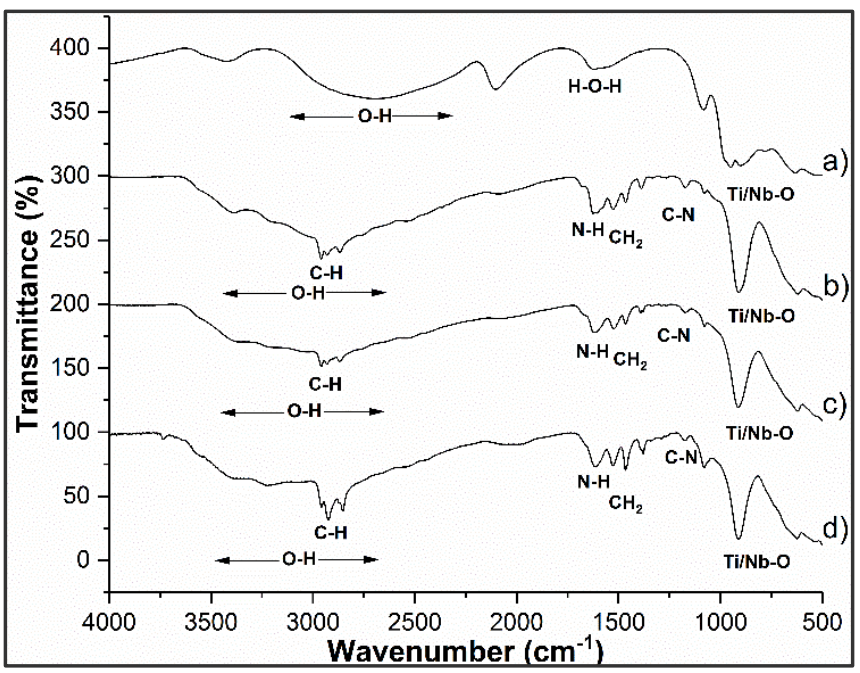

Figure 3 FTIR results: a) $\mathrm{HTiNbO}_{5}$ b) (butylNH$\left.{ }_{2}\right)_{\mathrm{x}} \mathrm{HTiNbO}_{5}$ c) (butylNH $\left.{ }_{2}\right)_{\mathrm{x}}\left(\mathrm{C}_{4} \mathrm{H}_{9} \mathrm{OH}\right)_{\mathrm{y}} \mathrm{HTiNbO}_{5}$ and $\left.\mathrm{d}\right)\left(\text { butylNH}{ }_{2}\right)_{\mathrm{x}}$ $\left(\mathrm{C}_{10} \mathrm{H}_{21} \mathrm{OH}\right)_{\mathrm{y}} \mathrm{HTiNbO}_{5}$. Y axis offset by multiples of 100 to prevent data overlap. Detailed description in main text

\section{Fourier transform infrared spectroscopy}

All samples were examined using FTIR (figure 3 and figure S6) with a clear difference between the $\mathrm{HTiNbO}_{5}$ and the intercalated samples being observed. The cluster of bands at $\approx 900,630$ and $515 \mathrm{~cm}^{-1}$ were identified by Lambert et al. 44 as originating from the octahedral modes of $\mathrm{TiO}_{6}$ and $\mathrm{NbO}_{6}$. M-O-H bending modes also identified by Lambert are seen at 946, 978 and $1080 \mathrm{~cm}^{-1}$. For $\mathrm{HTiNbO}_{5}$ the broad band at $\approx 2700 \mathrm{~cm}^{-1}$ shows strong $\mathrm{O}-\mathrm{H} \cdots \mathrm{O}$ hydrogen bonding between $\mathrm{TiNbO}_{5}^{-}$sheets and small band at $1610 \mathrm{~cm}^{-1}$ from $\mathrm{H}$ bonded $\mathrm{H}_{2} \mathrm{O}$. When amines and alcohols are intercalated these $\mathrm{H}$ bonds are broken so the $\mathrm{O}-\mathrm{H}$ stretch shifts to higher wavenumbers. The $\mathrm{O}-\mathrm{H}$ and $\mathrm{N}-\mathrm{H}$ now overlap causing the extremely broad band centered at $\approx 3000 \mathrm{~cm}^{-1}$ observed for the intercalated samples.

In addition to these bands there is a triple peak characteristic of $\mathrm{C}-\mathrm{H}$ stretches. The $\mathrm{C}-\mathrm{H}$ and $\mathrm{N}-\mathrm{H}$ bends appear at $\approx$ $1500 \mathrm{~cm}^{-1}$. As the spectra for amine intercalated and alcohol intercalated materials are similar FTIR cannot discriminate between intercalated species.

\section{Thermogravimetric analysis data}

In addition to FTIR, TGA was carried out (Figures 4 and $\mathrm{S}_{7}$ ) with post-TGA XRD being used to assign final products. Analysis of these post-TGA XRD patterns showed that when cooled radiatively sample showed mixture of $\mathrm{TiO}_{2}$ and $\mathrm{Nb}_{2} \mathrm{O}_{5}$. Slow cooled samples however showed either $\mathrm{Ti}_{2} \mathrm{Nb}_{2} \mathrm{O}_{9}$ phase or $\mathrm{TiNbO}_{4}$ (rutile form). The determining factor appears to be the drop at approximately $800{ }^{\circ} \mathrm{C}$. If this drop is present with no recovery $\mathrm{TiNbO}_{4}$ is the final product. If some weight is recovered due to oxidation, $\mathrm{Ti}_{2} \mathrm{Nb}_{2} \mathrm{O}_{9}$ becomes the final product. The $\mathrm{Ti}_{2} \mathrm{Nb}_{2} \mathrm{O}_{9}$ phase is a well-known dehydration phase of $\mathrm{HTiNbO}_{5} .{ }^{45}$ Structurally the metal octahedra remain but the interlayer hydrogen bonds are replaced by corner sharing of octahedra between layers. Visually the $\mathrm{TiNbO}_{4}$ appears dark blue to black, characteristic of $\mathrm{Nb}^{4+}$ while $\mathrm{Ti}_{2} \mathrm{Nb}_{2} \mathrm{O}_{9}$ samples appear white. Reported synthesis conditions for $\mathrm{TiNbO}_{4}$ are

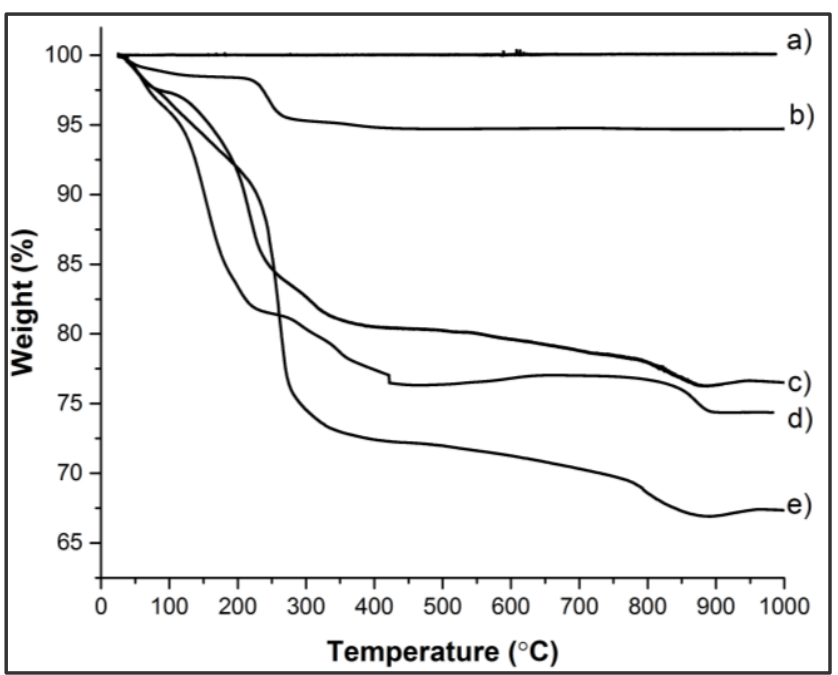

Figure 4 TGA results: a) $\mathrm{KTiNbO}_{5}$ b) $\mathrm{HTiNbO}_{5}$ c) $(\text { butylNH})_{2}$ $\left(\mathrm{C}_{4} \mathrm{H}_{9} \mathrm{OH}\right)_{\mathrm{y}} \mathrm{HTiNbO}_{5}$ d) (butylNH $\left.{ }_{2}\right)_{\mathrm{x}} \mathrm{HTiNbO}_{5}$ and e) (butylNH$)_{\mathrm{x}}\left(\mathrm{C}_{10} \mathrm{H}_{21} \mathrm{OH}\right)_{\mathrm{y}} \mathrm{HTiNbO}_{5}$ 
$\mathrm{NbO}_{2}$ and $\mathrm{TiO}_{2}$ heated to $650^{\circ} \mathrm{C}$, then $950^{\circ} \mathrm{C}$ in an evacuated quartz tube. ${ }^{6}$ As the length of the carbon chain of the alcohol increases the initial ( $\mathrm{sub} 100{ }^{\circ} \mathrm{C}$ ) weight loss ascribed to surface water also increases.

The powders also change in their tactile behavior going from dry brittle ceramic at low carbon content to soft almost polymer powder at higher carbon contents. Above 100 ${ }^{0} \mathrm{C}$ interlayer water is lost before the organics begin to de-intercalate.

Comparing the intercalated phases to the parent $\mathrm{HTiNbO}_{5}$ the weight loss gradient change at approximately $230{ }^{\circ} \mathrm{C}$ is the loss of the proton as $1 / 2 \mathrm{H}_{2} \mathrm{O}$. For butylamine and lower alcohols this is almost a separate transition but for the higher alcohols merges into general weight loss. Overall after loss of surface water the process is shown in Figure 5 .

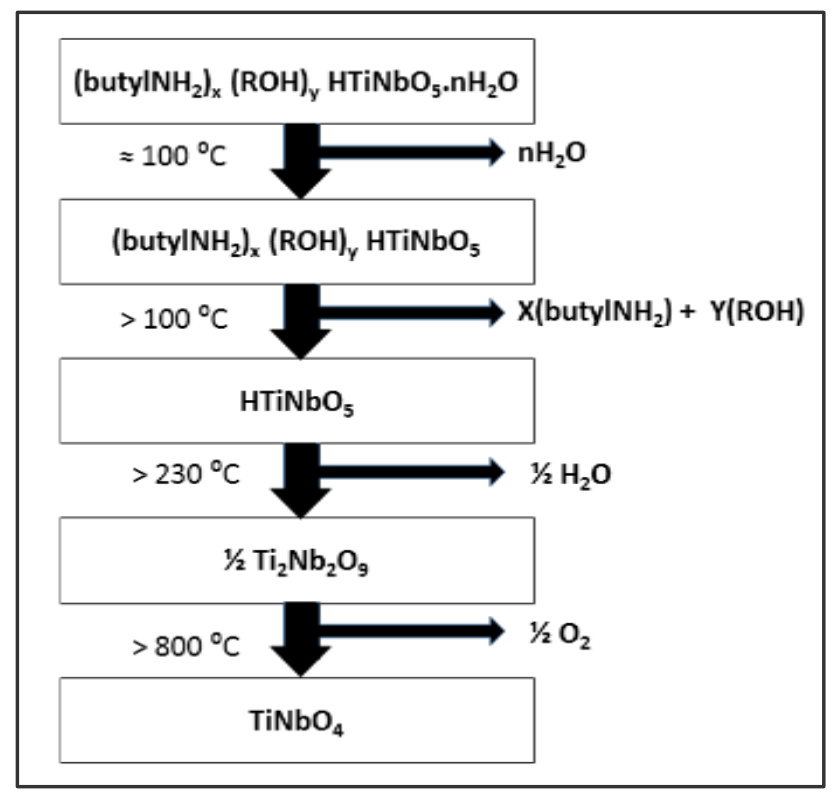

Figure 5 Weight loss steps after surface water loss

The last step which Chausson et al 47 asserts is remaining surface ammonium that leaves above $800{ }^{\circ} \mathrm{C}$. This does not occur for $\mathrm{HTiNbO}_{5}$ as there is no ammonium to begin with. When the ammonium has completely left by around 900 ${ }^{0} \mathrm{C}$ the powder has been reduced to $\mathrm{TiNbO}_{4}$. As the amount of intercalated amine $(\mathrm{x})$ is approximately 0.5 the equation for this process becomes;

\section{$\left(\mathrm{NH}_{2}\right)_{0.5} \mathrm{HTiNbO}_{5} \rightarrow \mathrm{TiNbO}_{4}+\mathrm{H}_{2} \mathrm{O}+1 / 4 \mathrm{~N}_{2}$}

\section{Elemental analysis results}

As the temperature ranges where butylamine and the alcohols de-intercalate overlap TGA alone is unable to resolve relative amounts of amine and alcohol. CHN analysis was therefore carried out with the results given in Table 1. The molecular masses obtained from CHN and TGA show good agreement.
Kikkawa and Koizumi ${ }^{4}$ have argued on the basis of space arguments that the material is only able to accommodate $1 / 2$ mole of butylamine per mole of $\mathrm{HTiNbO}_{5}$. From table 1 the amount of butylamine incorporated is 0.66 moles per mole of ceramic comparable to the 0.66 moles propylammonium to 1 mole $^{\mathrm{TiNbO}_{5}}{ }^{-}$of Nakato et al. ${ }^{49}$

Table 1 Elemental composition from $\mathrm{CHN}$ for (butylNH $)_{\mathbf{x}}(\mathrm{ROH})_{\mathrm{y}} \mathrm{HTiNbO}_{5}$ with calculated mass (RMM CHN) compared to calculated mass from TGA(RMM TGA)

\begin{tabular}{|c|c|c|c|c|}
\hline $\begin{array}{c}\text { Carbons per } \\
\text { Alcohol }\end{array}$ & $\begin{array}{c}\text { Moles } \\
\text { butylamine (x) }\end{array}$ & $\begin{array}{c}\text { Moles } \\
\text { Alcohol (y) }\end{array}$ & $\begin{array}{c}\text { RMM } \\
\text { CHN }\end{array}$ & $\begin{array}{c}\text { RMM } \\
\text { TGA }\end{array}$ \\
\hline Butylamine & $0.66(1)$ & 0 & $269.3(3)$ & $269.2(5)$ \\
\hline 1 & $0.528(4)$ & $0.24(5)$ & $264(1)$ & $264(1)$ \\
\hline 2 & $0.529(7)$ & $0.11(3)$ & $263.5(5)$ & $263.3(7)$ \\
\hline 3 & $0.535(8)$ & $0.08(1)$ & $264.0(5)$ & $269(1)$ \\
\hline 4 & $0.510(4)$ & $0.09(1)$ & $264.50(5)$ & $266(1)$ \\
\hline 5 & $0.540(7)$ & $0.10(1)$ & $268.50(5)$ & $267(3)$ \\
\hline 6 & $0.517(6)$ & $0.13(1)$ & $271(1)$ & $274.6(7)$ \\
\hline 7 & $0.506(7)$ & $0.206(9)$ & $279.0(5)$ & $277(2)$ \\
\hline 8 & $0.52(8)$ & $0.254(8)$ & $288.50(5)$ & $294(1)$ \\
\hline 9 & $0.464(7)$ & $0.30(1)$ & $294.0(5)$ & $292(2)$ \\
\hline 10 & $0.475(7)$ & $0.310(8)$ & $300(1)$ & $303(6)$ \\
\hline
\end{tabular}

Some excess amine is therefore able to pack with the intercalated amine. Washing procedures vary between reports with both Kikkawa ${ }^{48}$ and Nakato ${ }^{49}$ using acetone while Rebbah ${ }^{27}$ uses alcohol and in this report samples are not washed but dried. Lambert et $\mathrm{al}^{44}$ noticed a change in interlayer spacing (c/2) depending on whether samples were washed or not for their alkylammonium materials. For the butyl-ammonium case 20.37(6) Å unwashed versus 18.03 $\AA$ washed or $17.67 \AA$ when butylamine was used instead of butyl-ammonium chloride. Lambert proposed this was due to 'the occurrence of excess intercalation' which could be washed out. In this report when (butylNH $\left.)_{2}\right)_{\mathrm{XTiNbO}}$ is subsequently subjected to alcohol treatment the intercalated amount of butylamine drops to approximately 0.53 . This value is considerably closer to Lambert's ideal value of 0.55 and Kikkawa's 0.5. Thus approximately 0.5 butylamine binds in the accepted acid base fashion to the ceramic layers with the remaining 0.16 packing in an alkyl chain to alkyl chain fashion (excess intercalation). When the alcohol is introduced the packed butylamine is displaced leaving the alcohol now packed. A possible driving force for this could be the $\mathrm{OH}^{-}$group being better able to hydrogen bond with the remaining free proton on the opposing ceramic sheet. Or it could simply be a steric issue as the alcohol head group will be smaller than the corresponding amine group. As alcohol chain length increases the relative amount of butylamine decreases meaning the intercalation of larger chain alcohols is more favorable. 


\section{Discussion}

The method of alcohol insertion is described in this report as intercalation rather than grafiting ${ }^{19,22,50}$ or dissociative absorbtion ${ }^{33}$ as no $\mathrm{M}-\mathrm{O}-\mathrm{C}$ bonds are formed. This distinction was used by Tahara et $\mathrm{al}^{22}$ for amine intercalation and alcohol grafting in $\mathrm{H}_{2} \mathrm{La}_{2} \mathrm{Ti}_{3} \mathrm{O}_{10}$. In systems where grafting occurs the ceramic layer is often based on perovskite derivatives such as the Ruddlesden-Popper $\mathrm{H}_{2} \mathrm{La}_{2} \mathrm{Ti}_{3} \mathrm{O}_{10}{ }^{22}$ or the Triple-Layered $\mathrm{HCa}_{2} \mathrm{Nb}_{3} \mathrm{O}_{10} . \mathrm{XH}_{2} \mathrm{O}$. ${ }^{0}$ An important structural difference between these perovskite derivatives and $\mathrm{HTiNbO}_{5}$ can be found in how the metal oxide octahedra are connected. In perovskite all octahedra are corner shared where in $\mathrm{HTiNbO}_{5}$ there are edge shared pairs (Figure 1). This significantly alters the interlayer space allowing easier access to the interlayer gallery for perovskite derivatives. The straight gallery contrasts with the kinked gallery in $\mathrm{HTiNbO}_{5}$. In some cases such as $\mathrm{HCa}_{2} \mathrm{Nb}_{3} \mathrm{O}_{10}{ }^{50}$ and $\mathrm{HLaNb}_{2} \mathrm{O}_{7},{ }^{11}$ this increased access coupled with increased acidity of pure $\mathrm{Nb}-\mathrm{O}$ sheets 33 allows direct hydrolysis-esterification reactions. These reactions are required to graft alcohols to ceramics. In $\mathrm{HTiNbO}_{5}$ however amines must first be intercalated to push apart the layers to allow intercalation of alcohols.

A common way to describe the effect of intercalation of amines is to look at a plot of interlayer space versus carbon chain length. ${ }^{27,44,48,52}$ In Figure 6, we show a similar plot for the present alcohol intercalation system using the model described in the previous section. Using this model two regions would be expected. First a plateau with interlayer spacing = butylamine interlayer spacing until the packed alcohol becomes larger than the butylamine. Then when the alcohol becomes larger than the butylamine the interlayer space increases in a linear fashion with a gradient similar to that observed for amines. Two regions are seen in the data. The lattice parameters for lower alcohols (filled squares figure 6) are indeed very similar to butylamine intercalate however the CHN analysis and the TGA show alcohol is being included.

For the present system the transition between the two regions occurs around 6 carbons not the expected 4. For comparison the expected value of plateau is shown by a dashed line and literature data for aliphatic primary amines are also given in Figure 6. Using linear fits the increase in interlayer space below hexanol can be fitted to $0.34(3) \mathrm{X}+16.7(1)$ and above hexanol to $1.7(2) \mathrm{X}+8.7(13)$. The gradient of the above hexanol region is comparable (within error) with the average gradient of aliphatic amines $1.97(8)$. The intercept values correspond to the c parameter for $\mathrm{HTiNbO}_{5}$ below hexanol while above hexanol the interlayer space $(\mathrm{c} / 2)$ value for $\mathrm{HTiNbO}_{5}$ of $8.3 \AA$ is seen. If the lower alcohols had no effect on the butylamine then the intercept would be that of (butylNH$)_{2} \mathrm{HTiNbO}_{5}(18.29 \AA$ ) and gradient would be o (rather than $0.34(3)$ ). This shows the effect that the alcohol has on the amine intercalation angle, as alcohol size decreases tilt angle increases. Taking this to the extreme when there are no carbons and a tilt angle of $\approx 90^{\circ}$ butylamine would be along ab plane. As there will be butylamine on both sides of the interlayer a $\mathrm{C}-\mathrm{H}$ bond from each side has to be accommodated in a

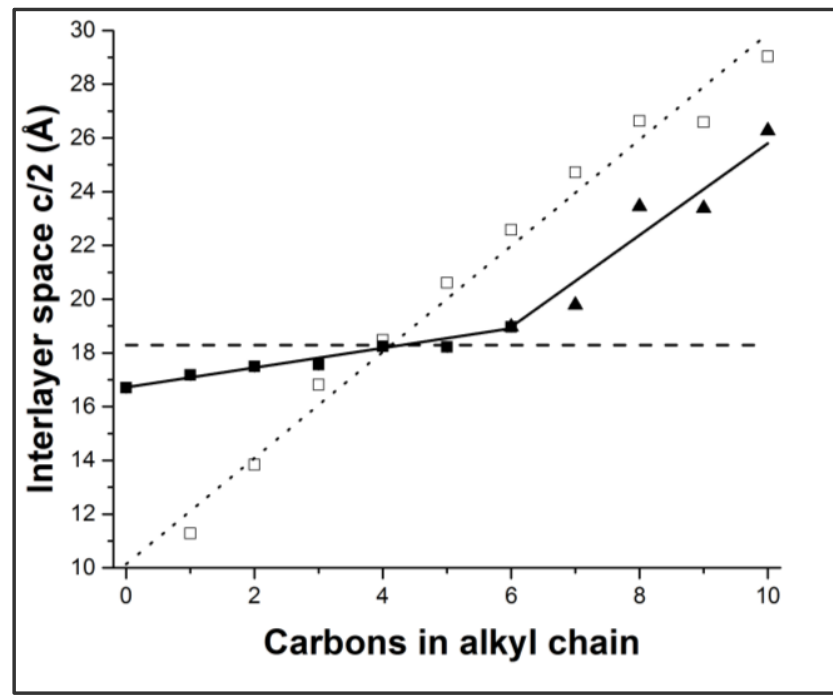

Figure 6 Interlayer distances (c/2) plotted against number of carbons in the alkyl chain. Filled squares/triangles are alcohol intercalated samples with solid lines being the linear fits described in main text. Empty squares are reference data $27,48,52$ for amine only intercalation with a dotted line fit. Dashed line interlayer spacing of butylamine intercalated material (this report).

( $\mathrm{C}-\mathrm{H} \mathrm{H}-\mathrm{C}$ ) fashion. This is in contrast to the experimental structure of $\mathrm{HTiNbO}_{5}$ where the proton links the sheets in a $\mathrm{O}-\mathrm{H}---\mathrm{O}$ fashion. The result of this is a theoretical doubling of the interlayer space for $\mathrm{C}=\mathrm{o}$ versus experimental $\mathrm{HTiNbO}_{5}((\mathrm{C}-\mathrm{H} \mathrm{H}-\mathrm{C})$ vs $(\mathrm{O}-\mathrm{H}---\mathrm{O}))$. As interlayer space is $\mathrm{c} / 2$ the intercept value for $\mathrm{C}=\mathrm{o}$ is the $\mathrm{c}$ parameter for $\mathrm{HTiNbO}_{5}$. As for the higher alcohols, increase in interlayer space is only due to alcohols increasing chain length then extrapolating back to no alcohol gives value of original non-intercalated ceramic $\mathrm{HTiNbO}_{5}$. The amine intercept of 10.1(5) $\AA$ is close to the 9.51 $\AA$ reported for $\mathrm{NH}_{4} \mathrm{TiNbO}_{5}($ $\mathrm{C}=\mathrm{o}$ amine $).{ }^{4}$

Amines are widely reported to intercalate at angles less than $90^{\circ}$ for $\mathrm{HTiNbO}_{5}$ when taking the $\mathrm{c}$ axis as being the vertical. Also as referred to previously only $50 \%$ of the possible proton binding sites are filled. When low chain alcohol gets in between these bound butylamine molecules it forces them to pack and tilt away from the $\mathrm{c}$ axis. The result of this is that instead of a plateau of interlayer space equal to (butylNH$)_{2}$ HTiNbO$_{5}$ a linear increase is observed. This increase continues past butanol to hexanol meaning this tilting creates extra space. Interlayer space (c parameters) for butanol and butylamine are similar but pentanol and hexanol are significantly reduced compared to their amine counterparts. A decrease in the tilt angle away from c axis was reported by Shangguan and Yoshida53 as the chain length of intercalated amine increases. Past hexanol the gradient changes drastically meaning past this point the alcohol on both sides is contributing to the packing and addition of an extra $\mathrm{CH}_{2}$ group now requires full expansion of space rather than altering the intercalation angle. 


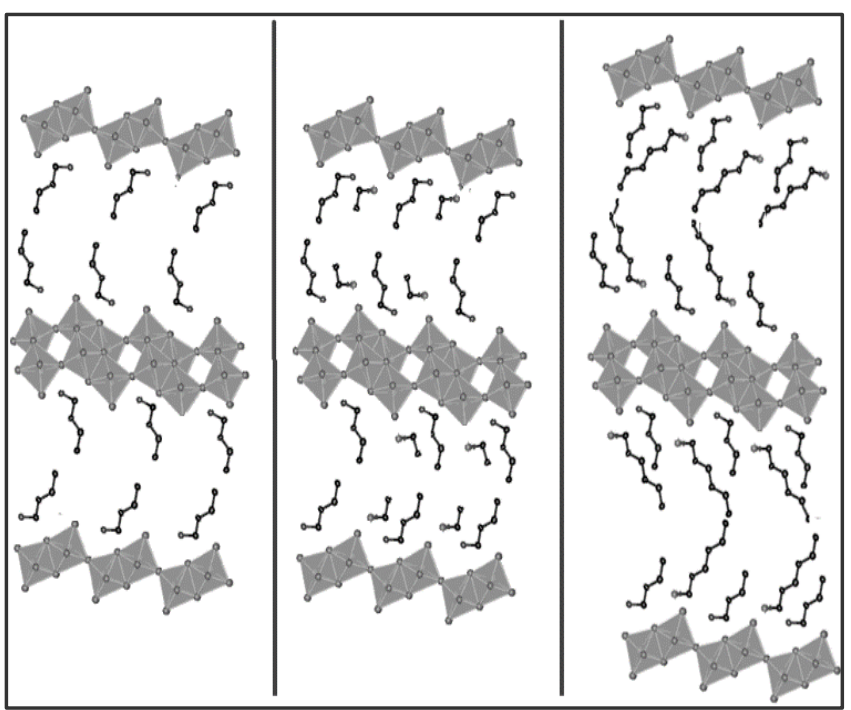

Figure 7 Schematic picture of the arrangement of the butylamine (left)based on Lambert's figure $6 b^{44}$ and lower alcohols (middle) and higher alcohols (right) intercalates between the $\mathrm{Ti} / \mathrm{Nb}$ oxide layers. For clarity the hydrogens have been omitted.

Schematically this is shown in Figure 7: first the butylamine intercalation, second the low alcohol causing amine intercalation angle to change. The angle away from c increases form a minimum at hexanol to maximum at methanol with the angle for butanol being similar to the angle for pure butylamine. Above hexanol the increase in interlayer space is predominantly caused by the alcohol chains coming in contact across the space rather than a change in angle (final panel of Figure 7). Experimentally this change in cause of interlayer increase is seen by the gradient change in Figure 6. Above hexanol gradient becomes similar to that of the pure amines where although tilting is present the increase is caused by increasing chain length (similar to Lamberts model 6b). ${ }^{44}$

\section{Conclusions}

Inorganic/organic hybrids of the form $\left(\mathrm{RNH}_{2}\right)_{\mathrm{x}}$ $(\mathrm{ROH})_{\mathrm{y}} \mathrm{HTiNbO}_{5}$ have been synthesized and characterized by X-ray diffraction, thermogravimetric analysis and $\mathrm{CHN}$ analysis. The alcohols intercalate into (butylNH$\left.)_{2}\right)_{x} \mathrm{HiNbO}_{5}$ rather than graft as observed previously in Ruddlesden-Popper phases. The amine is key to allowing alcohols into the structure. This anchoring behavior could be used to the synthetic chemists' advantage as any molecule with a primary alcohol side chain becomes a candidate for intercalation. The multistep method described in this report to intercalate alcohol in $\left(\mathrm{TiNbO}_{5}\right)^{-}$systems could be expanded to other layered systems. Any layered system where amines can intercalate such as $\mathrm{TiS}_{2}, \mathrm{TiNCl}$ and FeSe could also intercalate alcohol in a manner similar to $\mathrm{HTiNbO}_{5}$. The vast range of layered materials and molecules with a primary alcohol side chain opens up significant opportunities for new functional organic-ceramic hybrids.

\section{ASSOCIATED CONTENT}

Supporting Information consists of Rietveld information for $\mathrm{KTiNbO}_{5}$, lattice constants for (butylNH $\left.{ }_{2}\right)_{\mathrm{x}}(\mathrm{ROH})_{\mathrm{y}} \mathrm{HTiNbO}_{5}$, XRD patterns FTIR and TGA data.

This material is available free of charge via the Internet at http://pubs.acs.org.

\section{AUTHOR INFORMATION}

\section{Corresponding Author}

*christopher.2.thomas@aalto.fi

\section{ORCID}

\section{Chris I. Thomas 0ooo-0oo1-8090-4541}

Maarit Karppinen oooo-ooo3-1091-1169

\section{Author Contributions}

The manuscript was written through contributions of all authors. All authors have given approval to the final version of the manuscript.

\section{Notes}

The authors declare no competing financial interest.

\section{ACKNOWLEDGMENTS}

This work was financially supported by the European Research Council under the European Union's Seventh Framework Program (FP/2007-2013)/ERC Advanced Grant Agreement (No. 339478) and also from the Academy of Finland (No. 292431 and 303452 ).

\section{REFERENCES}

(1) Bizeto, M. A.; Shiguihara, A. L.; Constantino, V. R. L. Layered Niobate Nanosheets: Building Blocks for Advanced Materials Assembly. J. Mater. Chem. 2009, 19, 2512-2525.

(2) Selvam, T.; Inayat, A.; Schwieger, W. Reactivity and Applications of Layered Silicates and Layered Double Hydroxides. Dalt. Trans. 2014, 43, 10365-10387.

(3) Sugahara, Y. Chemical Processes Employing Inorganic Layered Compounds for Inorganic and Inorganic-Organic Hybrid Materials. J. Ceram. Soc. Japan 2014, 122, 523-529, 7.

(4) Matsumoto, A.; Odani, T.; Sada, K.; Miyata, M.; Tashiro, K. Intercalation of Alkylamines into an Organic Polymer Crystal. Nature 2000, 405, 328-330.

(5) Elkhalifah, A. E. I.; Bustam, M. A.; Azmi, M. S.; Murugesan, T. Carbon Dioxide Retention on Bentonite Clay Adsorbents Modified by Mono-, Di- and Triethanolamine Compounds. Adv. Mater. Res. 2014, 917, 115-122.

(6) Gonzalez Rodriguez, P.; Yuan, H.; van den Nieuwenhuizen, K. J. H.; Lette, W.; Schipper, D. J.; ten Elshof, J. E. Hybrid NAlkylamine Intercalated Layered Titanates for Solid Lubrication. ACS Appl. Mater. Interfaces 2016, 8, 2892628934 .

(7) Qin, Z.; Zhang, J.; Chi, H.; Cao, F. Organic--Inorganic Hybrid Nanocomposites Based on Chitosan Derivatives and Layered Double Hydroxides with Intercalated Phacolysin as Ocular Delivery System. J. Nanoparticle Res. 2015, 17, 468.

(8) Sheikh Mohd Ghazali, S. A. I.; Hussein, M. Z.; Sarijo, S. H. 3,4-Dichlorophenoxyacetate Interleaved into Anionic Clay for Controlled Release Formulation of a New Environmentally Friendly Agrochemical. Nanoscale Res. Lett. 2013, 8, 362.

(9) Tynell, T.; Giri, A.; Gaskins, J.; Hopkins, P. E.; Mele, P.; Miyazaki, K.; Karppinen, M. Efficiently Suppressed Thermal Conductivity in $\mathrm{ZnO}$ Thin Films via Periodic Introduction of 
Wan, C.; Gu, X.; Dang, F.; Itoh, T.; Wang, Y.; Sasaki, H.; Kondo, M.; Koga, K.; Yabuki, K.; Snyder, G. J.; Yang, R.; Koumoto, K. Flexible N-Type Thermoelectric Materials by Organic Intercalation of Layered Transition Metal Dichalcogenide TiS2. Nat. Mater. 2015, 14, 622-627.

(11) Yamanaka, S.; Umemoto, K.; Zheng, Z.; Suzuki, Y.; Matsui, H.; Toyota, N.; Inumaru, K. Preparation and Superconductivity of Intercalation Compounds of $\mathrm{TiNCl}$ with Aliphatic Amines. J. Mater. Chem. 2012, 22, 10752-10762. (12) Burrard-Lucas, M.; Free, D. G.; Sedlmaier, S. J.; Wright, J. D.; Cassidy, S. J.; Hara, Y.; Corkett, A. J.; Lancaster, T.; Baker, P. J.; Blundell, S. J.; Clarke, S. J. Enhancement of the Superconducting Transition Temperature of FeSe by Intercalation of a Molecular Spacer Layer. Nat Mater 2013, 12, 15-19.

(13) Vivanco, H. K.; Rodriguez, E. E. The Intercalation Chemistry of Layered Iron Chalcogenide Superconductors. J. Solid State Chem. 2016, 242, Part, 3-21.

(14) Hosomi, T.; Suematsu, H.; Fjellvag, H.; Karppinen, M.; Yamauchi, H. Identification of Superconducting Phases in the Ba-Ca-Cu-O System: An Unstable Phase with Tc[approximate] $126 \mathrm{~K}$ and Its Derivative with Tc[approximate]9o K. J. Mater. Chem. 1999, 9, 1141-1148.

(15) Matvejeff, M.; Lehtimäki, M.; Hirasa, A.; Huang, Y.-H.; Yamauchi, H.; Karppinen, M. New Water-Containing Phase Derived from the $\mathrm{Sr}_{3} \mathrm{Fe}_{2} \mathrm{O}_{7}-\delta$ Phase of the Ruddlesden-Popper Structure. Chem. Mater. 2005, 17, 27752779.

(16) Mohapatra, L.; Parida, K. A Review on the Recent Progress, Challenges and Perspective of Layered Double Hydroxides as Promising Photocatalysts. J. Mater. Chem. A Mater. Energy Sustain. 2016, 4, 10744-10766.

(17) Tanaka, A.; Kondo, J. N.; Domen, K. Photocatalytic Properties of Ion-Exchangeable Layered Oxides. Crit. Rev. Surf. Chem. 1995, 5, 305-326.

(18) Miyamoto, N.; Kuroda, K.; Ogawa, M. Visible Light Induced Electron Transfer and Long-Lived Charge Separated State in Cyanine Dye/Layered Titanate Intercalation Compounds. J. Phys. Chem. B 2004, 108, 4268-4274.

(19) Wang, Y.; Wang, C.; Wang, L.; Hao, Q.; zhu, X.; Chen, X.; Tang, K. Preparation of Interlayer Surface Tailored Protonated Double-Layered Perovskite $\mathrm{H}_{2} \mathrm{CaTa}_{2} \mathrm{O}_{7}$ with NAlcohols, and Their Photocatalytic Activity. RSC Adv. 2014, 4, 4047-4054.

(20) Chaleshtori, M. Z.; Masud, S. M. S.; Saupe, G. B. Using New Porous Nanocomposites for Photocatalytic Water Decontamination. Mater. Res. Soc. Symp. Proc. 2008, 1145E, 36.

(21) Leroux, F.; Taviot-Gueho, C. Fine Tuning between Organic and Inorganic Host Structure: New Trends in Layered Double Hydroxide Hybrid Assemblies. J. Mater. Chem. 2005, 15, 3628-3642.

(22) Tahara, S.; Ichikawa, T.; Kajiwara, G.; Sugahara, Y. Reactivity of the Ruddlesden-Popper Phase $\mathrm{H}_{2} \mathrm{La}_{2} \mathrm{Ti}_{3} \mathrm{O}_{1}$ o with Organic Compounds: Intercalation and Grafting Reactions. Chem. Mater. 2007, 19, 2352-2358.

(23) Jacobson, A. J.; Johnson, J. W.; Lewandowski, J. T. Intercalation of the Layered Solid Acid $\mathrm{HCa}_{2} \mathrm{Nb}_{3} \mathrm{O}_{10}$ by Organic Amines. Mater. Res. Bull. 1987, 22, 45-51.

(24) Yang, J.-H.; Pei, Y.-R.; Piao, H.; Vinu, A.; Choy, J.-H. Molecular Orientation of Intercalants Stabilized in the Interlayer Space of Layered Ceramics: 1-D Electron Density Simulation. J. Korean Ceram. Soc 2016, 53, 417-428.

(25) Rebbah, H.; Desgardin, G.; Raveau, B. ATiMO5 Oxides: Cation Exchangers. Mater. Res. Bull. 1979, 14, 1125-1131.

(26) Colin, J.-F.; Pralong, V.; Caignaert, V.; Hervieu, M.; Raveau, B. A Novel Layered Titanoniobate LiTiNbO5: Topotactic Synthesis and Electrochemistry versus Lithium. Inorg. Chem. 2006, 45, 7217-7223.

(27) Rebbah, H.; Borel, M. M.; Raveau, B. Intercalation of
Alkylammonium Ions and Oxide Layers Titanoniobate(-) (TiNbO5)-. Mater. Res. Bull. 1980, 15, 317-321.

(28) Zhang, X.; Liu, C.; Liu, L.; Zhang, D.; Zhang, T.; Xu, X.; Tong, Z. Intercalation of Methylene Blue into Layered Potassium Titanoniobate $\mathrm{KTiNbO}_{5}$ : Characterization and Electrochemical Investigation. J. Mater. Sci. 2010, 45, 16041609.

(29) Ma, J.; Ban, X.; Li, J.; Jiang, H.; Zhang, T.; Liu, L.; Xu, X.; Tong, Z. Preparation, Thermostability, and Spectroscopic Properties of Rhodamine 6G Intercalated Titanoniobate Nanocomposite. J. Mater. Sci. 2o11, 46, 2431-2436.

(30) Tong, Z.; Shichi, T.; Takagi, K. Visible-Light Induced ChargeSeparation between Consecutively Cast Porphyrin and Methyl Viologen Multilayered Titanoniobate Hybrid Films. J. Phys. Chem. B 2002, 106, 13306-13310.

(31) Tong, Z.; Shichi, T.; Oshika, K.; Takagi, K. A Nanostructured Hybrid Material Synthesized by the Intercalation of Porphyrin into Layered Titanoniobate. Chem. Lett. 2oo2, 31, 876-877.

(32) Liu, C.; Wu, L.; Chen, J.; Liang, J.; Li, C.; Ji, H.; Hou, W. The Nanocomposite of Polyaniline and Nitrogen-Doped Layered $\mathrm{HTiNbO}_{5}$ with Excellent Visible-Light Photocatalytic Performance. Phys. Chem. Chem. Phys. 2014, 16, 13409-13417.

(33) Takagaki, A.; Sugisawa, M.; Lu, D.; Kondo, J. N.; Hara, M.; Domen, K.; Hayashi, S. Exfoliated Nanosheets as a New Strong Solid Acid Catalyst. J. Am. Chem. Soc. 2003, 125, 54795485 .

(34) Dias, A. S.; Lima, S.; Carriazo, D.; Rives, V.; Pillinger, M.; Valente, A. A. Exfoliated Titanate, Niobate and Titanoniobate Nanosheets as Solid Acid Catalysts for the Liquid-Phase Dehydration of D-Xylose into Furfural. J. Catal. 2006, 244, 230-237.

(35) Rebbah, H.; Borel, M. M.; Bernard, M.; Raveau, B. Intercalation of Nitrogen Derivatives in the Structure of Layers of Hydrogen Titanium Peroxyniobate (HTiNbO5). Rev. Chim. Miner. 1981, 18, 109-117.

(36) Le Bail, A.; Duroy, H.; Fourquet, J. L. Ab-Initio Structure Determination of LiSbWO6 by X-Ray Powder Diffraction. Mater. Res. Bull. 1988, 23, 447-452.

(37) Rietveld, H. M. A Profile Refinement Method for Nuclear and Magnetic Structures. J. Appl. Cryst. 1969, 2, 65-71.

(38) Von Dreele, R. B.; Larson, A. C. General Structure Analysis System (GSAS). Los Alamos Natl. Lab. 20oo, 86-748.

(39) Toby, B. H. EXPGUI, a Graphical User Interface for GSAS. J. Appl. Crystallogr. 2001, 34, 210-213.

(40) Wadsley, A. D. Alkali Titanoniobates. The Crystal Structures of KTiNbO 5 and KTi3NbO9. Acta Crystallogr. 1964, 17, 623628.

(41) Rebbah, H.; Pannetier, J.; Raveau, B. Localization of Hydrogen in the Layer Oxide Hydrogen Titaniniobate (HTiNbO5). J. Solid State Chem. 1982, 41, 57-62.

(42) Sugimoto, W.; Hirota, N.; Mimuro, K.; Sugahara, Y.; Kuroda K. Synthesis of Reduced Layered Titanoniobates KTi1-xNb1+xO5. Mater. Lett. 1999, 39, 184-187.

(43) Rebbah, H.; Desgardin, G.; Raveau, B. Nonstoichiometric Oxides with a Layer Structure: The Compounds A1-x(Ti1$\mathrm{xM} 1+\mathrm{x}) \mathrm{O}_{5}$. J. Solid State Chem. 1980, 31, 321-328.

(44) Lambert, J.-F.; Deng, Z.; d'Espinose, J.-B.; Fripiat, J. J. The Intercalation Process of N-Alkyl Amines or Ammoniums within the Structure of KTiNbO5. J. Colloid Interface Sci. 1989, 132, 337-351.

(45) Fang, M.; Kim, C. H.; Mallouk, T. E. Dielectric Properties of the Lamellar Niobates and Titanoniobates $\mathrm{AM}_{2} \mathrm{Nb}_{3} \mathrm{O}_{10}$ and $\operatorname{ATiNbO}_{5}(\mathrm{~A}=\mathrm{H}, \mathrm{K}, \mathrm{M}=\mathrm{Ca}, \mathrm{Pb})$, and Their Condensation Products Ca4Nb6O19 and Ti2Nb2O9. Chem. Mater. 1999, 11, 1519-1525.

(46) Sakata, K. Study of the Phase Transition in NbxTi1-xO2. J. Phys. Soc. Japan 1969, 26, 1067.

(47) Chausson, S.; Caignaert, V.; Retoux, R.; Rueff, J.-M.; Le Pluart, L.; Madec, P.-J.; Jaffres, P.-A. Polyethylene Nanocomposites Based on Intercalation of N-Alkyl Amines 
within $\mathrm{KTiNbO}_{5}$ Structure. Polymer (Guildf). 2008, 49, 488496.

(48) Kikkawa, S.; Koizumi, M. Organic Intercalation on Layered Compound KTiNbO5. Phys. B+C 1981, 105, 234-237.

(49) Nakato, T.; Miyata, H.; Kuroda, K.; Kato, C. Synthesis of Methylviologen-HTiNbO5 Intercalation Compound and Its Photochemical Behavior. React. Solids 1988, 6, 231-238.

(50) Tahara, S.; Sugahara, Y. Interlayer Surface Modification of the Protonated Triple-Layered Perovskite $\mathrm{HCa}_{2} \mathrm{Nb}_{3} \mathrm{O}_{10} \cdot \mathrm{xH}_{2} \mathrm{O}$ with N-Alcohols. Langmuir 2003, 19, 9473-9478.

(51) Takahashi, S.; Nakato, T.; Hayashi, S.; Sugahara, Y.; Kuroda, K. Formation of Methoxy-Modified Interlayer Surface via the
Reaction between Methanol and Layered Perovskite

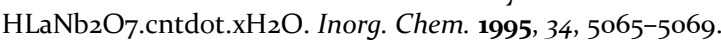

(52) Tagaya, H.; Saito, K.; Kuwahara, T.; Kadokawa, J.; Chiba, K. Intercalation of Organic Compounds into Layered Titanoniobate KTiNbO5. Catal. Today 1993, 16, 463-470.

(53) Shangguan, W.; Yoshida, A. Modification of the Interlayer in $\mathrm{HTiNbO}_{5}$ and Its Physicochemical Characterization. Mol. Cryst. Liq. Cryst. Sci. Technol. Sect. A. Mol. Cryst. Liq. Cryst. 2000, 341, 219-224. 


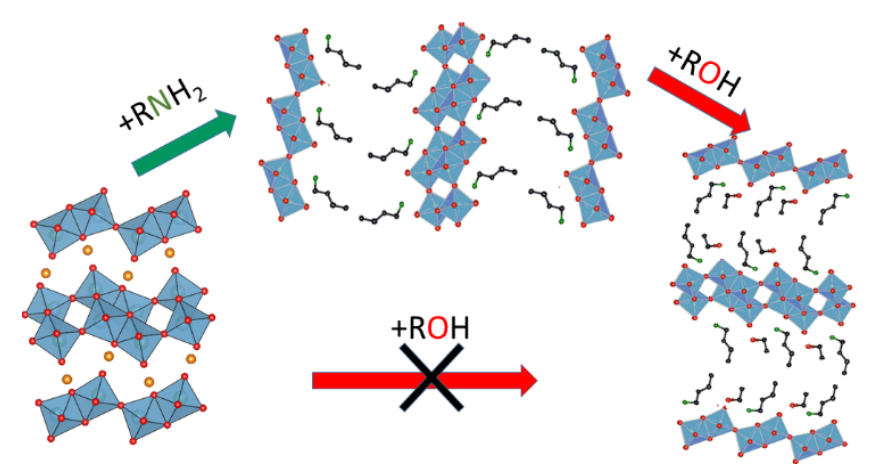

Primary alcohols have been intercalated between the layers of $\mathrm{HTiNbO}_{5}$ for the first time via a two-step process. As alcohols are less basic than amines they are unable to go via the one step acid base mechanism instead requiring an amine intermediate. Intercalation causes a significant expansion of the unit cell followed by XRD. This shows how alcohols can be used to influence the interlayer space of oxide sheets in functional layered oxide ceramics. 